\title{
Study of Rainfall from TRMM Microwave Imager Observation over India
}

\author{
Anoop Kumar Mishra ${ }^{1}$ and Rajesh Kumar ${ }^{2}$ \\ ${ }^{1}$ Research Center for Environmental Changes, Academia Sinica, Taipei 115, Taiwan \\ ${ }^{2}$ Remote Sensing \& Aerial Surveys, Mission-1B, Geological Survey of India, Govt. of India, Ministry of Mines, Bangalore, India
}

Correspondence should be addressed to Anoop Kumar Mishra, daksha112@gmail.com

Received 2 August 2012; Accepted 5 September 2012

Academic Editors: G. Chisham and A. Streltsov

Copyright (C) 2012 A. K. Mishra and R. Kumar. This is an open access article distributed under the Creative Commons Attribution License, which permits unrestricted use, distribution, and reproduction in any medium, provided the original work is properly cited.

This paper presents a technique to estimate precipitation over Indian land $\left(6-36^{\circ} \mathrm{N}, 65-99^{\circ} \mathrm{E}\right)$ at $0.25^{\circ} \times 0.25^{\circ}$ spatial grid using tropical rainfall measuring mission (TRMM) microwave imager (TMI) observations. It adopts the methodology recently developed by Mishra (2012) to monitor the rainfall over the land portion. Regional scattering index (SI) developed for Indian region and polarization corrected temperature (PCT) have been utilized in this study. These proxy rain variables (i.e., PCT and SI) are matched with rainfall from precipitation radar (PR) to relate rain rate with PCT, SI, and their combination. Retrieval techniques have been developed using nonlinear relationship between rain and proxy variables. The results have been compared with the observations (independent of training data set) from PR. Results have also been validated with the observations from automatic weather station (AWS) rain gauges. It is observed from the validation results that nonlinear algorithm using single variable SI underestimates the low rainfall rates (below $20 \mathrm{~mm} / \mathrm{h}$ ) but overestimates the high rain rates (above $20 \mathrm{~mm} / \mathrm{h}$ ). On the other hand, algorithm using PCT overestimates the high rain rates (above $25 \mathrm{~mm} / \mathrm{h}$ ). Validation results with rain gauges show a CC of 0.68 and RMSE of $4.76 \mathrm{~mm}$ when both SI and PCT are used.

\section{Introduction}

High rainfall events in India have increased by $50 \%$ during past 50 years [1]. Hence an accurate prediction of high rainfall event is essential for prevention and management of disasters. In India, there is a low spatial density of automatic rain gauges and Doppler Weather Radars (DWRs). So satellitebased rainfall estimates are highly valuable for synoptic situations. Rainfall estimations based on infrared (IR) measurements from satellite have large errors because IR radiances from cloud tops have only indirect and weak relationship with surface rainfall $[2,3]$. On the other hand, satellite microwave measurements provide more direct estimates of rainfall. Microwave algorithms are generally classified as statistical or physical [4]. Statistical algorithms (e.g., [5]) use observed data to derive an empirical relationship between brightness temperature and precipitation. Physical algorithm (e.g., [6-9]) uses a data base of radiative transfer calculations based on atmospheric profiles, which are compared with an observed set of brightness temperature. The higher the number of channels used, the greater the chances of finding an accurate hydrometeor profile in data base. Precipitation estimation algorithms from microwaves using radiative transfer models have been developed by Wu and Weinmann [10] and Kummerow et al. [11]. Most of the microwave rainfall techniques have been based on tropical, subtropical, or continental convective rainfall concentrating on accurate retrieval of higher rainfall rates. Grody [12] used microwave observations to suggest that scattering index (SI) is a good indicator of rainfall. On the basis of Grody's algorithm, Ferraro and Marks [13] developed a global scattering index separately for land and ocean to estimate the rainfall. Chen et al. [14] used SI for rainfall retrieval over Taiwan. Mishra et al. [15] found that global scattering indices were highly variable for different regions and seasons and hence developed a regional scattering index for the Indian land and associated oceanic regions. A nonlinear relationship was developed between SI and rain rate, separately for the Indian land 
and associated oceanic regions. Comparison with rain gauge observations showed a correlation coefficient of 0.68 and root mean square error of $9.35 \mathrm{~mm} / \mathrm{h}$ over Indian land. The validation with rain gauge observations confirmed that regional based scattering indices were able to retrieve the rainfall over Indian region better than the global scattering index developed by Ferraro and Marks [13]. Grody [16] introduced the surface independent polarization-corrected temperature (PCT) to estimate rainfall. Spencer et al. [17] and Kidd and Barret [18] used PCT imagery at $85 \mathrm{GHz}$ microwave brightness temperature to analyze the rainfall signatures. Kumar et al. [19] utilized PCT to explore the precipitation feature over Indian region from special sensor microwave/imager (SSM/I) observations. Nativi et al. [20] utilized PCT, SI, polarization difference, and combination of brightness temperatures to estimate the rainfall from SSM/I observations. Tsai et al. [21] used PCT depression to estimate rainfall over Taiwan during Typhoon by the application of nonlinear regression. These studies showed the possibilities for rainfall estimation at the highest possible resolution over nonscattering surface by identification of depressed PCT values. Biscaro and Morales [22] applied the probability matching method (PMM) developed by Calheiros and Zawadzki [23] to derive the relation between PCT and rain rate. The main concept behind the PMM was to relate two independent variables through their probability frequency. Liu and Curry [24] proposed the use of both scattering and emission signatures from microwave observations to estimate the rainfall. Todd and Bailey [25] used depression in PCT to estimate the rainfall rate by the application of nonlinear regression. Yao et al. [26] utilized the PCT and SI from TRMM microwave observations to estimate the rainfall over Tibetan Plateau assuming a linear relationship between the radar rain rate, PCT, and SI. They observed that high rainfall rates were underestimated most of the time by the application of linear algorithm. Zhao et al. [27] used both SI and PCT to monitor the high rainfall events over China on the basis of linear regression between rain rate and combination of SI and PCT using TMI observation. Mahesh et al. [28] used both SI and PCT to estimate the rainfall using artificial neural network. Recently, heavy rainfall events during cyclonic cases over Indian ocean using SI and PCT were studied by Mishra [29]. He found that nonlinear algorithm performs better than linear algorithm in retrieving the rainfall over oceanic region (especially heavy rainfall). In the present study, TRMM data are analyzed to estimate the rainfall over Indian land based on nonlinear algorithm using PCT, SI, and combination of them.

\section{Data Used}

TRMM data is used in this study. The tropical rainfall measuring mission (TRMM) is a joint space mission between National Aeronautics and Space Administration (NASA) and the Japan Aerospace Exploration Agency (JAXA) designed to monitor and study tropical rainfall. It was launched in 1997 into a near circular orbit. Along with other sensors it carries TRMM microwave imager (TMI) and first space borne precipitation radar (PR). In the present study surface rainfall data of Precipitation Radar Version 6 (2A25) [30] is used during the years 2008-2011. Brightness temperature data of TMI at 19, 22, and $85 \mathrm{GHz}$ channels are also utilized for the same period in this study. In the present study, the Indian Space Research Organization-Designed Automatic Weather Station (AWS) rain gauge data is used. Among many other sources, AWS has a tipping bucket rain gauge with unlimited rain measuring capacity. At present, more than 300 AWSs are deployed in clusters working all over specific regions in India. Temporal resolutions of these rain gauge observations are 15 minutes. For validation of present algorithm, AWS rain gauge data during 2009 and 2010 are used. The point measurement by AWS rain gauges is averaged within $0.25^{\circ} \times 0.25^{\circ}$ spatial grid. Area of study and AWS distribution over India is shown in Figure 1.

\section{Methodology}

Rain signatures based on scattering and polarization properties of the microwave radiation from the hydrometeors are identified. Region-specific scattering index developed by Mishra et al. [15] was utilized for scattering-based rain signature.This scattering index for the Indian region is given by following equation:

$$
\begin{aligned}
\mathrm{SI}= & \left(448.6809+\left(-1.5456 \times T_{19 V}\right)+\left(-0.6020 \times T_{22 V}\right)\right. \\
& \left.+\left(0.0055 \times\left(T_{22 V}\right)^{2}\right)\right)-T_{85 V},
\end{aligned}
$$

where $T_{f}$ is vertically polarized brightness temperature in ${ }^{\circ} \mathrm{K}$ at frequency " $f$."

Another rain signature based on polarization and scattering property of the microwaves at $85 \mathrm{GHz}$ brightness temperature proposed by Spencer et al. [17] is defined as follows:

$$
\text { PCT }=(1+0.818) T_{85 \mathrm{~V}}-0.818 T_{85 \mathrm{H}},
$$

where $T_{85 \mathrm{~V}}$ and $T_{85 \mathrm{H}}$ are vertically and horizontally polarized brightness temperatures at $85 \mathrm{GHz}$, respectively.

Now, these variables SI and PCT are matched with rainfall rates from $\mathrm{PR}$ in $0.25^{\circ} \times 0.25^{\circ}$ grid box over Indian land. Coastal areas are excluded from the area of study.

Figures 2 and 3 show the relationship between rainfall rate versus SI and PCT, respectively. Lines drawn over scatters are lines of best fit. For this purpose, total number of 5764 collocated data points from PR rain rate and SI, PCT, and combination of SI and PCT during the years 2008-2011 are used.

Nonlinear equations using SI, PCT, and their combination with rainfall rate $(\mathrm{mm} / \mathrm{h})$ from $\mathrm{PR}$ are as follows:

$$
\begin{gathered}
\text { Rain }=0.0001 \times(\mathrm{SI})^{2.7496}, \\
\text { Rain }=-5.02+(585.39 \times \exp (-0.0168 \times \mathrm{PCT})), \\
\text { Rain }=-6.75+(89.15 \times \exp (-0.0088 \times \mathrm{PCT})) \\
+\left(0.0001 \times(\mathrm{SI})^{2.5977}\right) .
\end{gathered}
$$




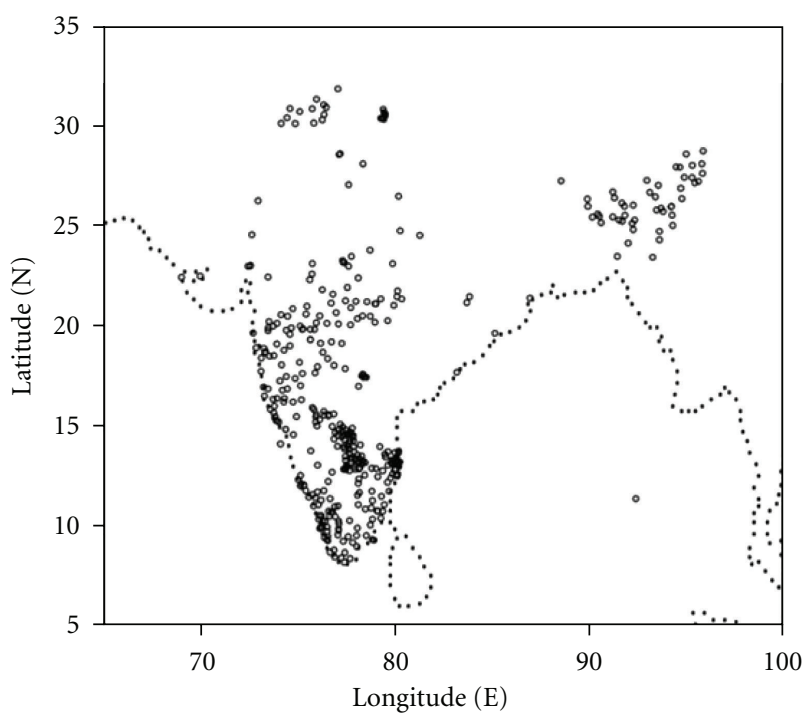

FIgURE 1: Area of study and density of AWS rain gauges.

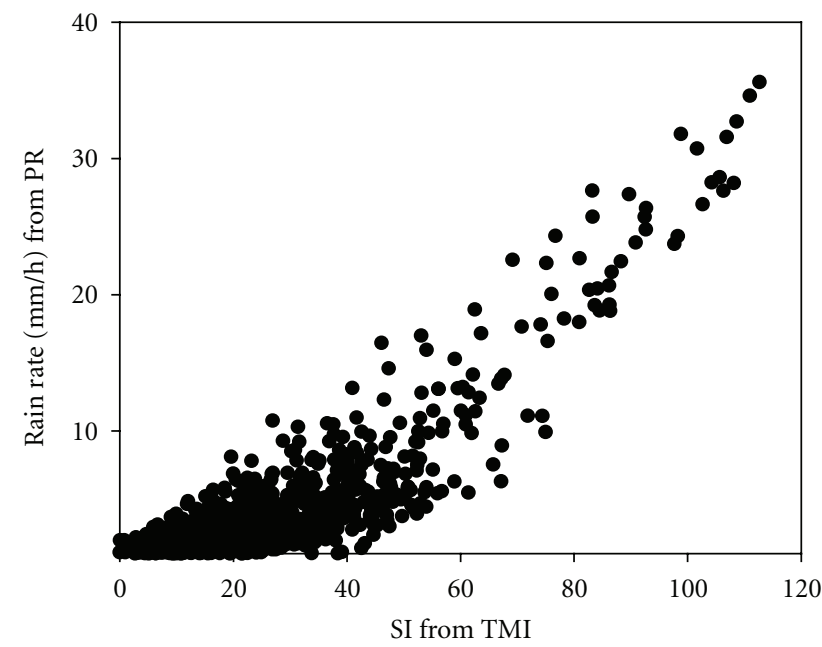

FIGURe 2: Scatter plot between rain rate $(\mathrm{mm} / \mathrm{h})$ from PR and SI from TMI.

TABLE 1: Error statistics of the training data sets.

\begin{tabular}{lccc}
\hline Regression equation & $\begin{array}{c}\text { Data } \\
\text { points }\end{array}$ & $\begin{array}{c}\text { Correlation } \\
\text { coefficients }\end{array}$ & $\begin{array}{c}\text { Root mean } \\
\text { square error } \\
(\mathrm{mm} / \mathrm{h})\end{array}$ \\
\hline $\begin{array}{l}\text { Nonlinear equation } \\
\text { using SI (3) }\end{array}$ & 5764 & 0.762 & 2.061 \\
$\begin{array}{l}\text { Nonlinear equation } \\
\text { using PCT (4) }\end{array}$ & 5764 & 0.786 & 1.952 \\
$\begin{array}{l}\text { Nonlinear equation } \\
\text { using SI and PCT (5) }\end{array}$ & 5764 & 0.842 & 1.764 \\
\hline
\end{tabular}

Correlation coefficients of $0.76,0.78$, and 0.84 and root mean square error of $2.06,1.95$, and $1.76 \mathrm{~mm} / \mathrm{h}$ are observed for the above equations (3), (4), and (5), respectively, (see Table 1).

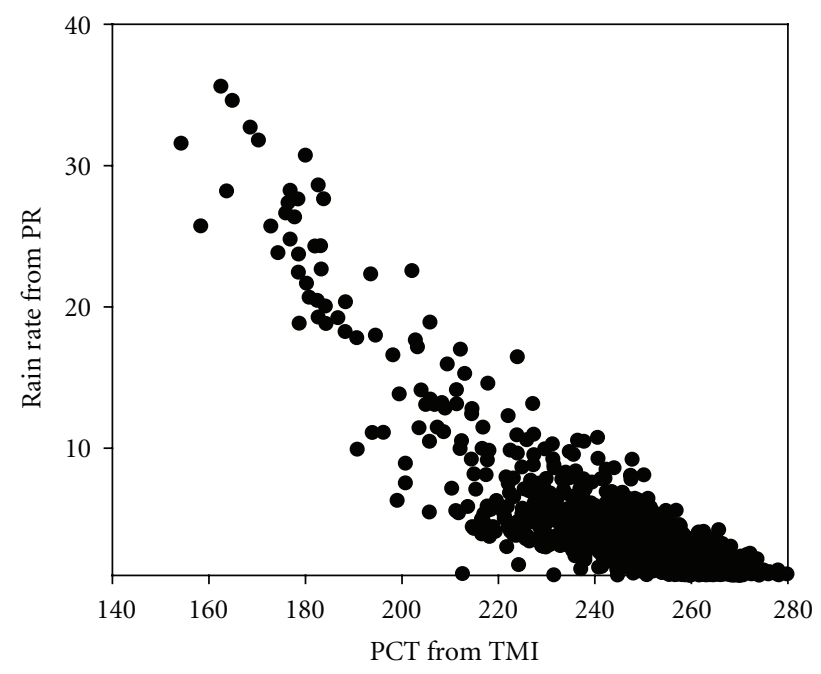

Figure 3: Scatter plot between rain rate $(\mathrm{mm} / \mathrm{h})$ from PR and PCT from TMI.

\section{Results and Discussions}

Regression equations (3)-(5) are used to study the rainfall over land portion of the Indian region. We have tested the algorithm by comparing the rainfall obtained from above equation with that from independent (of training data sets) PR observations. For this purpose, PR observations were averaged at $0.25^{\circ} \times 0.25^{\circ}$ grid box. Total 6842 independent data sets (different from the points used for the training purpose) during the years 2008-2011 are selected. Figures 4(a)4 (c) show scatter plots between $\mathrm{PR}$ rain rate and rain rates retrieved using nonlinear regression ((3), (4), and (5)). Lines drawn over scatters are lines of best fit. From Figure 4(a), it may be observed that nonlinear regression using SI only underestimates the lighter rain rates $(1-10 \mathrm{~mm} / \mathrm{h})$. It may also be noted that higher rain rates (above $25 \mathrm{~mm} / \mathrm{h}$ ) are overestimated using SI only. Careful observation of Figure 4(b) reveals that rainfall using PCT compares well with $\mathrm{PR}$ at low-to-moderate rainfall rates (below $15 \mathrm{~mm} / \mathrm{h}$ ) but overestimates the high rainfall rates (above $25 \mathrm{~mm} / \mathrm{h}$ ). It may further be observed from Figure 4(c) that algorithm using both SI and PCT compares well with PR observations at each rainfall range. Algorithm using both SI and PCT performs better than those using either SI or PCT for precipitation observations over Indian region. Error statistics of this comparison are listed in Table 2. It may be observed from Table 2 that statistical comparison with PR shows a CC of $0.72,0.74,0.78 \mathrm{RMSE}$ of $3.18,2.76,1.89 \mathrm{~mm} / \mathrm{h}$ and bias of $2.17,1.96,1.18 \mathrm{~mm} / \mathrm{h}$ using SI, PCT, and combination of SI and PCT, respectively. It may be concluded that algorithm using both SI and PCT shows superior comparison with PR than that using either SI or PCT.

We analyzed the accuracy of this technique to monitor the rainfall at different ranges using bin analysis. For this purpose, independent PR observations are averaged in seven ranges, that is, $0-5,5-10,10-15,15-20,20-25,25-30$, and 30 to above $30(\mathrm{~mm} / \mathrm{h})$. The total number of observations in each bin is almost constant, so that statistical weight is same. 


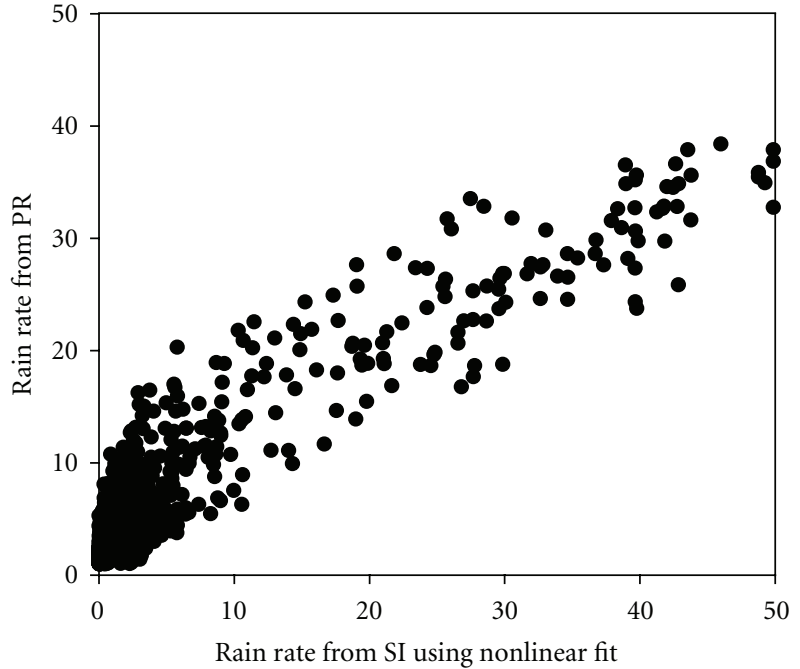

(a)

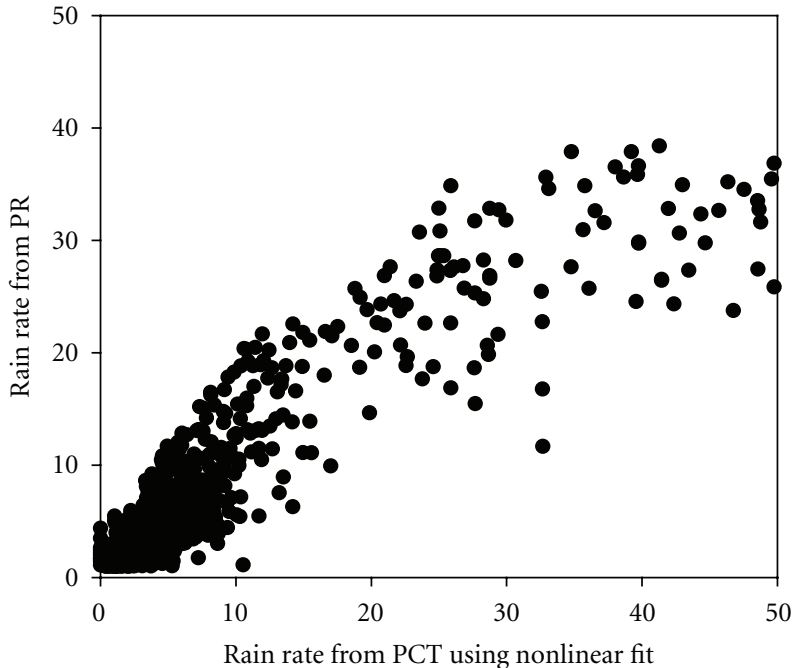

(b)

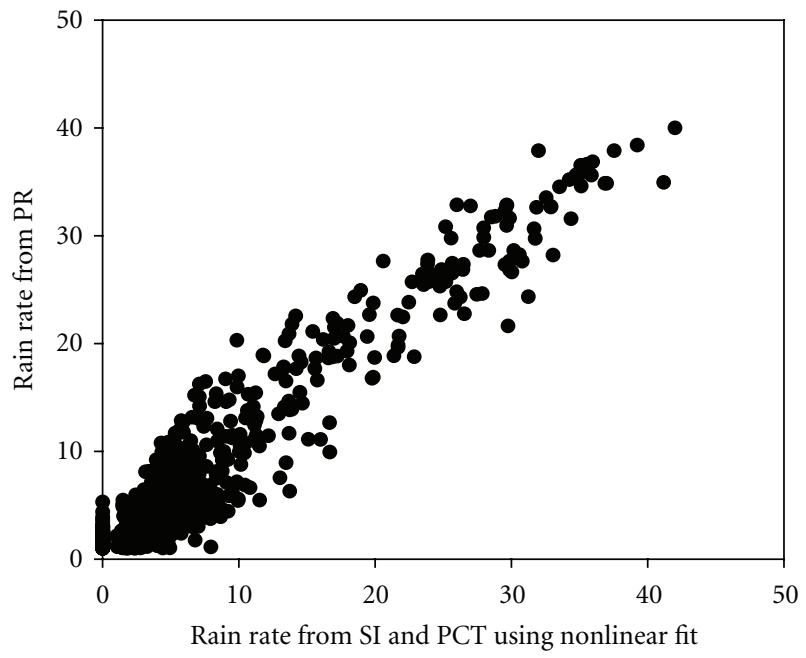

(c)

Figure 4: (a) Scatter plot between rain rate ( $\mathrm{mm} / \mathrm{h}$ ) from PR and that from nonlinear regression using SI, (b) same as Figure 4(a), but using PCT only, and (c) same as Figure 4(a), but using both SI and PCT.

TABLE 2: Statistical comparison of algorithms using nonlinear regression with PR observations (validation data sets).

\begin{tabular}{lcccc}
\hline Algorithm applied & No. of data points & Correlation coefficients & Root mean square error (RMSE) (mm/h) & Bias (mm/h) \\
\hline $\begin{array}{l}\text { Nonlinear regression using SI } \\
\text { only }\end{array}$ & 6842 & 0.722 & 3.186 & 2.171 \\
$\begin{array}{l}\text { Nonlinear regression using PCT } \\
\text { only }\end{array}$ & 6842 & 0.741 & 2.763 \\
$\begin{array}{l}\text { Nonlinear regression using both } \\
\text { SI and PCT }\end{array}$ & 6842 & 0.784 & 1.896 \\
\hline
\end{tabular}

Figure 5 shows scatter plot of RMSE and averaged rainfall rates. It is observed that algorithm using both SI and PCT shows the least error.

Finally, rainfall rates obtained from linear and nonlinear algorithms are validated using AWS rain gauges. The total number of 2516 data points is selected for this purpose during high rainfall events of 2009 and 2010. Figures 6(a)6(c) represent scatter plots between rain rate from rain gauge and that from nonlinear regression using SI, PCT, and both SI and PCT, respectively. Lines drawn over scatters are lines of best fit. It may be concluded from these figures that nonlinear regression using multiproxy rain variable shows better 


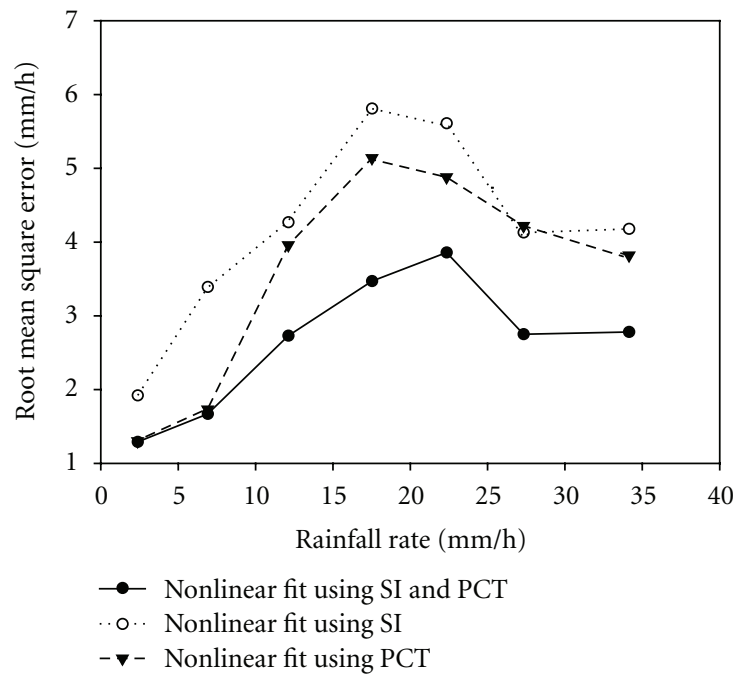

FIGURE 5: Scatter plot between binned rain rate $(\mathrm{mm} / \mathrm{h}$ ) from PR and RMSE obtained from binned rain rate ( $\mathrm{mm} / \mathrm{h}$ ) from PR and those from SI, PCT, and combination of SI and PCT using linear and nonlinear regression.

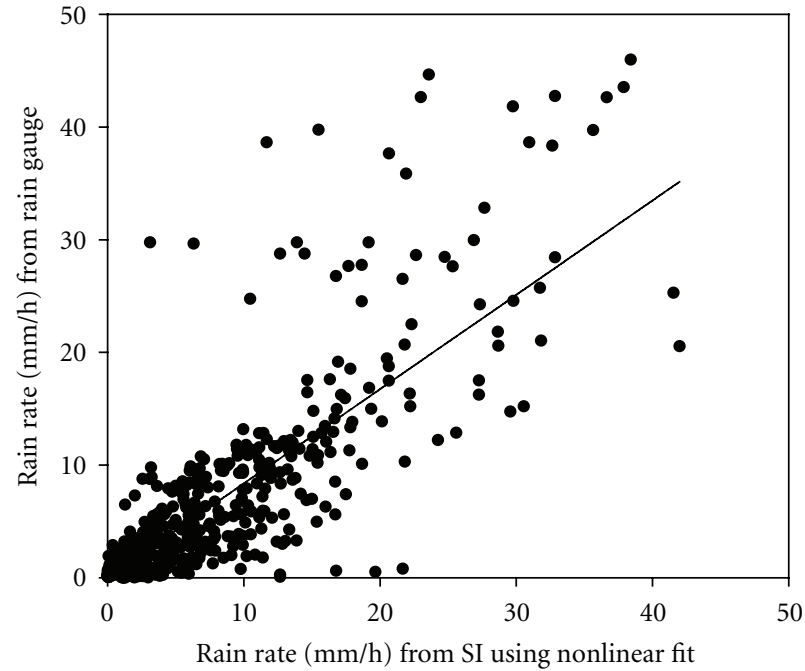

(a)

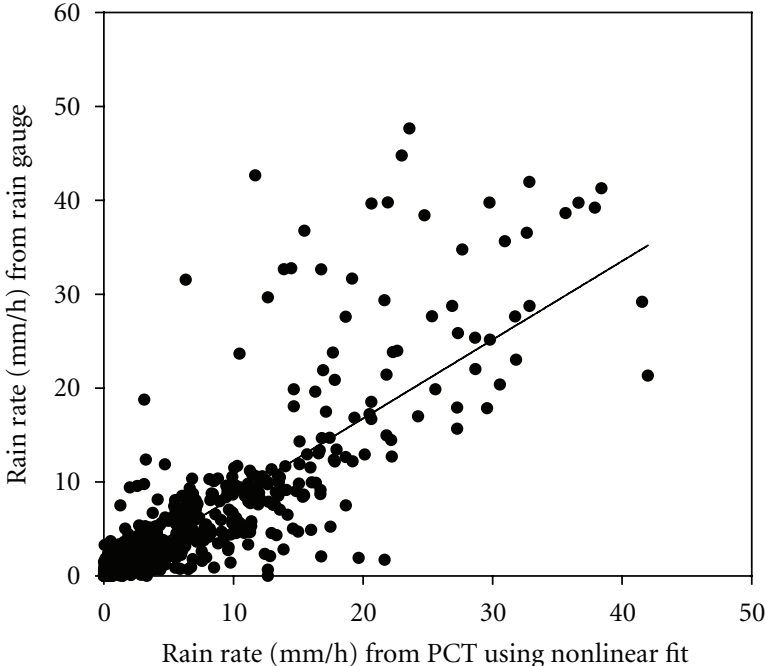

(b)

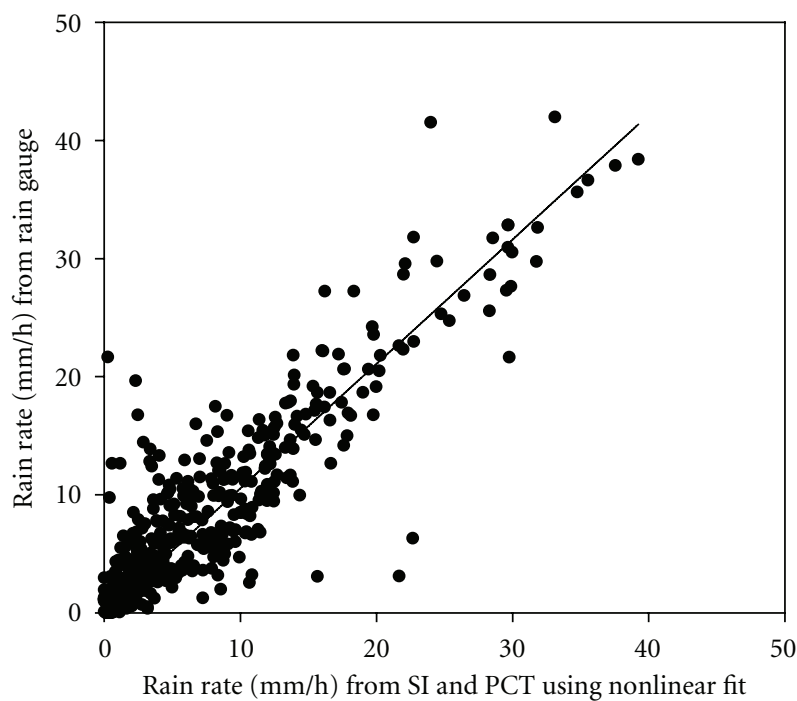

(c)

FIGURE 6: (a) Scatter plot between rain rate $(\mathrm{mm} / \mathrm{h})$ from rain gauge and that from nonlinear regression using SI, (b) same as Figure 6(a), but using PCT, and (c) same as Figure 6(a), but using SI and PCT. 
TABLE 3: Statistical comparison of algorithms using nonlinear regression with AWS rain gauge observations.

\begin{tabular}{|c|c|c|c|c|}
\hline Algorithm applied & No. of data points & Correlation coefficients & Root mean square error (RMSE) $(\mathrm{mm} / \mathrm{h})$ & $\operatorname{Bias}(\mathrm{mm} / \mathrm{h})$ \\
\hline $\begin{array}{l}\text { Nonlinear regression using SI } \\
\text { only }\end{array}$ & 2516 & 0.654 & 7.542 & 6.653 \\
\hline $\begin{array}{l}\text { Nonlinear regression using PCT } \\
\text { only }\end{array}$ & 2516 & 0.673 & 6.763 & 4.563 \\
\hline $\begin{array}{l}\text { Nonlinear regression using both } \\
\text { SI and PCT }\end{array}$ & 2516 & 0.682 & 4.763 & 3.987 \\
\hline
\end{tabular}

comparison with gauges as compared to that using single variable. Error statistics are listed in Table 3. Correlation coefficients (CC) of $0.65,0.67$, and 0.68 , RMSE of 7.542, 6.763 , and 4.763 , and bias of $6.65,4.56$, and $3.98 \mathrm{~mm} / \mathrm{h}$ are observed with rain gauge from the measurement of SI, PCT, and combination of SI and PCT, respectively, using nonlinear regression.

It may be inferred from validation results that multiple rain signatures are required to monitor the rainfall over Indian land region.

\section{Conclusion}

The technique described in the present study emphasizes the use of multiple signatures rain from microwave observations to monitor the rainfall over Indian land. Region-specific SI and PCT are used for this purpose. Validation with PR and rain gauge shows that single proxy rain variable (SI or PCT) cannot represent the precipitation at all ranges. The present technique has indicated that multiple proxy rain variables successfully monitor the rainfall. This algorithm can be used to monitor the rainfall over tropical region using more frequent passes from microwave analysis and detection of rain and atmospheric structures (MADRASs) channel of recently launched Indo-French mission Megha-Tropiques.

\section{Acknowledgments}

TRMM data from NASA/GSFC used in this study is thankfully acknowledged. Useful discussions with Professor J. Srinivasan are thankfully acknowledged. The authors also acknowledge the MOSDAC for providing the ISRO AWS rain gauge data.

\section{References}

[1] B. N. Goswami, V. Venugopal, D. Sangupta, M. S. Madhusoodanan, and P. K. Xavier, "Increasing trend of extreme rain events over India in a warming environment," Science, vol. 314, no. 5804, pp. 1442-1445, 2006.

[2] A. Mishra, R. M. Gairola, A. K. Varma, and V. K. Agarwal, "Remote sensing of precipitation over Indian land and oceanic regions by synergistic use of multi-satellite sensors," Journal of Geophysical Research, vol. 115, Article ID D08106, 12 pages, 2010.

[3] A. K. Mishra, R. M. Gairola, A. K. Varma, and V. K. Agarwal, "Improved rainfall estimation over the Indian region using satellite infrared technique," Advances in Space Research, vol. 48, no. 1, pp. 49-55, 2011.

[4] A. Mishra, Remote Sensing of Precipitation from Satellite Infrared and Microwave Observations Over Indian Tropics, Lambert Academic Publication, Berlin, Germany, 2012.

[5] R. F. Adler, G. J. Huffman, and P. R. Keehn, "Global tropical rain estimates from microwave-adjusted geosynchronous IR data," Remote Sensing Reviews, vol. 11, no. 1-4, pp. 125-152, 1994.

[6] K. F. Evans, J. Turk, T. Wong, and G. L. Stephens, "A Bayesian approach to microwave precipitation profile retrieval," Journal of Applied Meteorology, vol. 34, no. 1, pp. 260-278, 1995.

[7] C. Kummerow, Y. Hong, W. S. Olson et al., "The evolution of the Goddard profiling algorithm (GPROF) for rainfall estimation from passive microwave sensors," Journal of Applied Meteorology, vol. 40, no. 11, pp. 1801-1820, 2001.

[8] A. Mugnai and E. A. Smith, "Radiative transfer to space through a precipitating cloud at multiple microwave frequencies. Part1: model description," Journal of Applied Meteorology, vol. 27, no. 9, pp. 1055-1073, 1988.

[9] N. Viltard, C. Burlaud, and C. D. Kummerow, "Rain retrieval from TMI brightness temperature measurements using a TRMM PR-based database," Journal of Applied Meteorology and Climatology, vol. 45, no. 3, pp. 455-466, 2006.

[10] R. Wu and J. A. Weinman, "Microwave radiances from precipitating clouds containing aspherical ice, combined phase, and liquid hydrometeors," Journal of Geophysical Research, vol. 89, no. 5, pp. 7170-7178, 1984.

[11] C. Kummerow, R. A. Mack, and I. M. Hakkarinen, "A selfconsistency approach to improve microwave rainfall rate estimation from space," Journal of Applied Meteorology, vol. 28, no. 9, pp. 869-884, 1989.

[12] N. C. Grody, "Classification of snow cover and precipitation using the special sensor Microwave Imager," Journal of Geophysical Research, vol. 96, no. 4, pp. 7423-7435, 1991.

[13] R. R. Ferraro and G. F. Marks, "The development of SSM/I rain rate retrieval algorithms using ground based radar measurements," Journal of Atmospheric and Oceanic Technology, vol. 12, pp. 755-770, 1995.

[14] W. J. Chen, M. D. Tsai, G. R. Liu, and M. H. Chang, "The study of rainfall derived from TRMM Microwave Imager data over Taiwan land-using Scattering Index method," Atmospheric Sciences, vol. 33, pp. 277-300, 2005.

[15] A. Mishra, R. M. Gairola, A. K. Varma, A. Sarkar, and V. K. Agarwal, "Rainfall retrieval over Indian land and oceanic regions from SSM/I microwave data," Advances in Space Research, vol. 44, no. 7, pp. 815-823, 2009.

[16] N. C. Grody, "Precipitation monitoring over land from satellites by microwave radiometry," in Proceedings of the International Geoscience and Remote Sensing Symposium (IGARSS 
'84), ESA SP-215, pp. 417-423, Strasbourg, France, August 1984.

[17] R. W. Spencer, H. M. Goodman, and R. E. Hood, "Precipitation retrieval over land and ocean with the SSM/I: identification and characteristics of the scattering signal," Journal of Atmospheric and Oceanic Technology, vol. 6, no. 2, pp. 254-273, 1989.

[18] C. Kidd and E. C. Barret, "The use of passive microwave imagery in rainfall monitoring," Remote Sensing Reviews, vol. 4, no. 2, pp. 415-450, 1990.

[19] R. Kumar, R. M. Gairola, A. Mishra, A. K. Varma, and I. M. L. Das, "Evaluation of precipitation features in high-frequency SSM/I measurements over Indian land and oceanic regions," IEEE Geoscience and Remote Sensing Letters, vol. 6, no. 3, pp. 373-377, 2009.

[20] S. Nativi, E. C. Barrett, and M. J. Beaumont, "Microwave monitoring of rainfall: intercomparisons of data from the Chilbolton radar and the DMSP-SSM/I," Meteorological Applications, vol. 4, no. 2, pp. 101-114, 1997.

[21] M. D. Tsai, W. J. Chen, and J. L. Wang, "Implementing polarization-corrected temperature into typhoon rainfall estimates over Taiwan from TRMM/TMI data," Terrestrial, Atmospheric and Oceanic Sciences, vol. 21, no. 4, pp. 697-712, 2010.

[22] T. S. Biscaro and C. A. Morales, "Continental passive microwave-based rainfall estimation algorithm: application to the Amazon Basin," Journal of Applied Meteorology and Climatology, vol. 47, no. 7, pp. 1962-1981, 2008.

[23] R. V. Calheiros and I. Zawadzki, "Reflectivity-rain rate relationships for radar hydrology in Brazil," Journal of Climate \& Applied Meteorology, vol. 26, no. 1, pp. 118-132, 1987.

[24] G. Liu and J. A. Curry, "An investigation of the relationship between emission and scattering signals in SSM/I data," Journal of the Atmospheric Sciences, vol. 55, no. 9, pp. 1628-1643, 1998.

[25] M. C. Todd and J. O. Bailey, "Estimates of rainfall over the United Kingdom and surrounding seas from the SSM/I using the polarization corrected temperature algorithm," Journal of Applied Meteorology, vol. 34, no. 6, pp. 1254-1265, 1995.

[26] Z. Yao, W. Li, Y. Zhu, B. Zhao, and Y. Chen, "Remote sensing of precipitation on the Tibetan Plateau using the TRMM Microwave Imager," Journal of Applied Meteorology, vol. 40, no. 8, pp. 1381-1392, 2001.

[27] B. Zhao, Z. Yao, W. Li et al., "Rainfall retrieval and flooding monitoring in China using TRMM Microwave Imager (TMI)," Journal of the Meteorological Society of Japan, vol. 79, no. 1, pp. 301-315, 2001.

[28] C. Mahesh, S. Prakash, V. Sathiyamoorthy, and R. M. Gairola, "Artificial neural network based microwave precipitation estimation using scattering index and polarization corrected temperatures," Atmospheric Research, vol. 102, no. 3, pp. 358$364,2011$.

[29] A. Mishra, "Estimation of heavy rainfall during cyclonic storms from microwave observations using nonlinear approach over Indian Ocean," Natural Hazards, vol. 63, no. 2, pp. 673-683, 2012.

[30] T. Iguchi, T. Kozu, R. Meneghini, J. Awaka, and K. I. Okamoto, "Rain-profiling algorithm for the TRMM precipitation radar," Journal of Applied Meteorology, vol. 39, no. 12, pp. 2038-2052, 2000. 

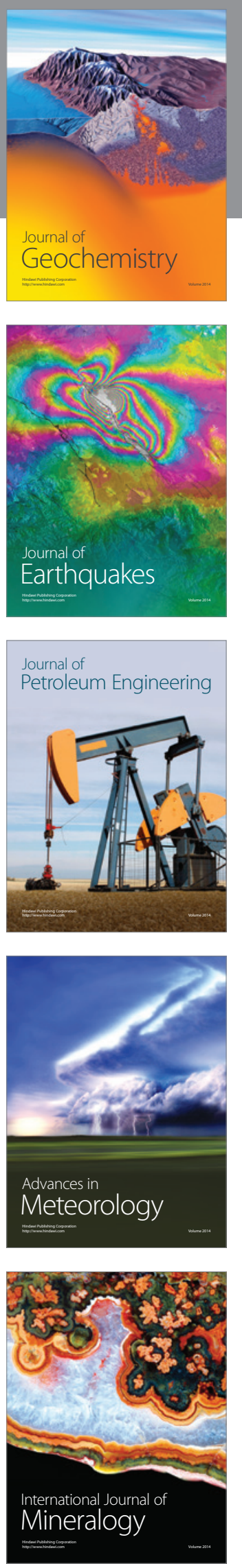
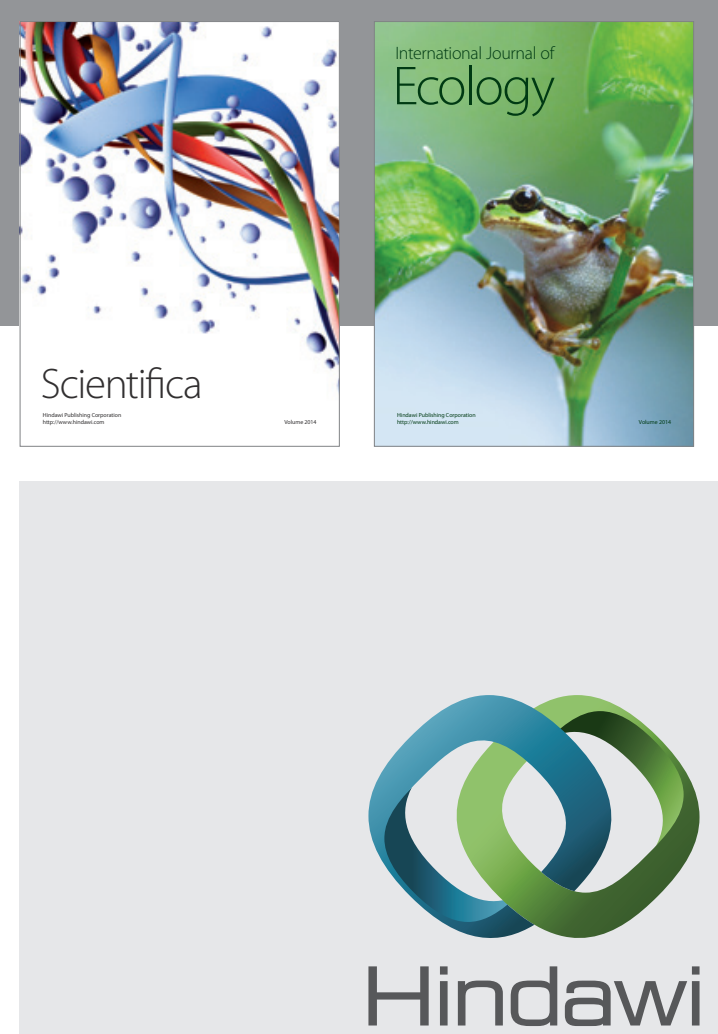

Submit your manuscripts at http://www.hindawi.com
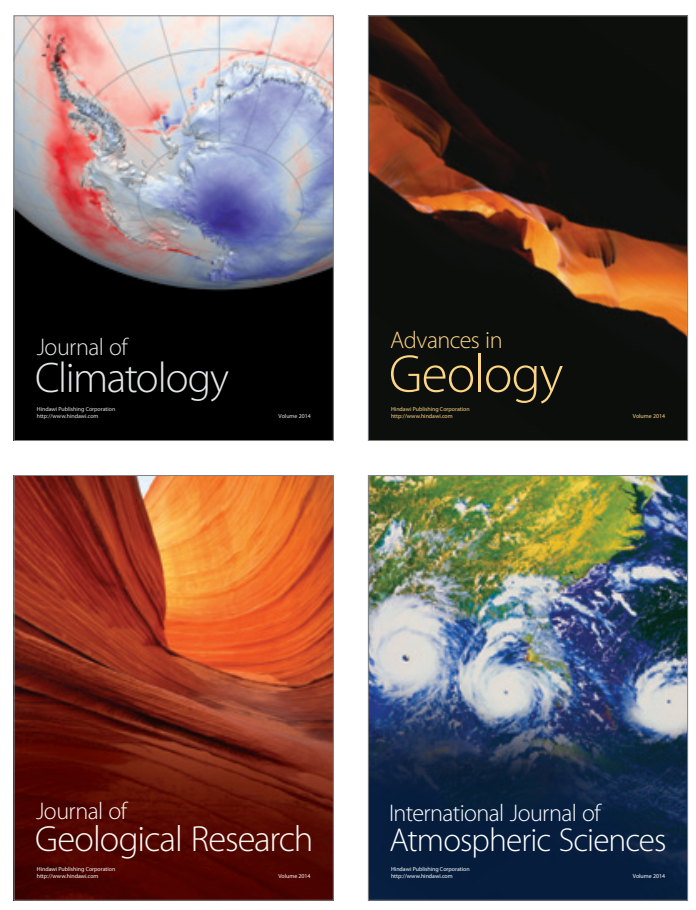
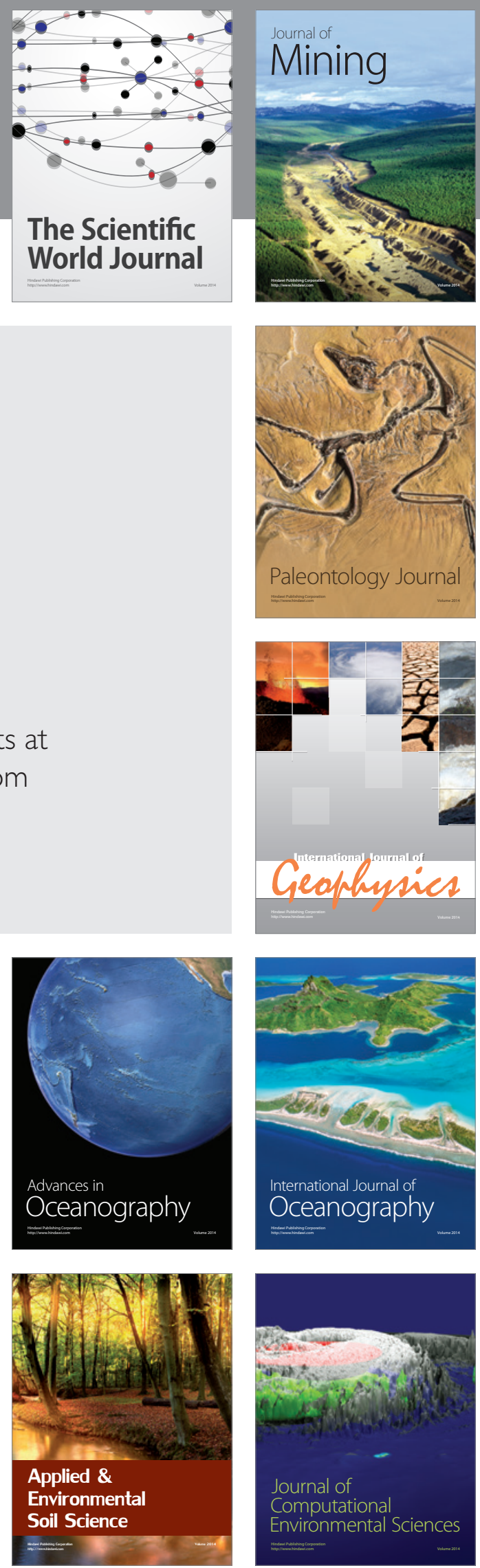